

\title{
Silicon epitaxy on H-terminated Si (100) surfaces at $250{ }^{\circ} \mathrm{C}$
}

\author{
Xiao Deng ${ }^{\mathrm{a}, \mathrm{b}}$, Pradeep Namboodiri ${ }^{\mathrm{b}}$, Kai $\mathrm{Li}^{\mathrm{b}}$, Xiqiao Wang ${ }^{\mathrm{b}, \mathrm{c}}$, Gheorghe Stan $^{\mathrm{b}}$, Alline F. Myers ${ }^{\mathrm{b}}$, Xinbin \\ Cheng ${ }^{\mathrm{a}}$, Tongbao $\mathrm{Li}^{\mathrm{a}}$ and Richard M. Silver \\ ${ }^{a}$ School of Physics Science and Engineering, Tongji University, Shanghai 200092, People's Republic of China \\ ${ }^{b}$ National Institute of Standards and Technology, Gaithersburg, Maryland 20899, United States \\ ${ }^{c}$ University of Maryland, College Park, Maryland 20740, United States
}

\begin{abstract}
Low temperature Si epitaxy has become increasingly important due to its critical role in the encapsulation and performance of buried nanoscale dopant devices. We demonstrate epitaxial growth up to nominally $25 \mathrm{~nm}$, at $250^{\circ} \mathrm{C}$, with analysis at successive growth steps using STM and cross section TEM to reveal the nature and quality of the epitaxial growth. STM images indicate that growth morphology of both $\mathrm{Si}$ on Si and Si on Hterminated $\mathrm{Si}(\mathrm{H}: \mathrm{Si})$ is epitaxial in nature at temperatures as low as $250{ }^{\circ} \mathrm{C}$. For $\mathrm{Si}$ on $\mathrm{Si}$ growth at $250{ }^{\circ} \mathrm{C}$, we show that the Si epitaxial growth front maintains a constant morphology after reaching a specific thickness threshold. Although the in-plane mobility of silicon is affected on the $\mathrm{H}$ : Si surface due to the presence of $\mathrm{H}$ atoms during initial sub-monolayer growth, STM images reveal long range order and demonstrate that growth proceeds by epitaxial island growth albeit with noticeable surface roughening.
\end{abstract}

Keywords: Low temperature Si epitaxy, scanning tunneling microscope, H terminated Si surfaces

\section{Introduction}

Recent advances in atomic scale patterning of phosphorus dopants on hydrogen terminated Si (100) surfaces using STM lithography have resulted in a variety of atomic scale devices, including wires ${ }^{[1],[2]}$, quantum dots ${ }^{[3],[4]}$ and single atom transistors $^{[5]}$. As the building blocks for the Si based Kane quantum computer ${ }^{[6],[7],[8]}$, most of these approaches rely on patterning a hydrogen resist layer ${ }^{[9],[10]}$ and selectively adsorbing dopant atoms in areas defined by lithographic patterns ${ }^{[11],[12]}$. Electrical performance of these devices depends strongly on the quality of the silicon matrix surrounding the device layer. It is necessary, therefore, to embed devices in high quality crystalline Si in order to isolate atomically doped regions from surfaces and interfaces that can potentially disturb their local electronic environment as well as to fully activate the dopant atoms.

(C) 2016. This manuscript version is made available under the Elsevier user license http://www.elsevier.com/open-access/userlicense/1.0/ 
Low temperature silicon epitaxy has become widely recognized as a suitable method to suppress dopant segregation and diffusion during growth to achieve near atomic scale doped devices ${ }^{[13],[14]}$. It has also been reported that epitaxial growth of silicon can occur at temperatures as low as room temperature ${ }^{[15]}$, and that Si film growth at room temperature up to several monolayers' thickness has been successfully used as a locking layer to maintain ultra-sharp dopant profiles ${ }^{[16]}$. Electrical measurements by McKibbin et al. ${ }^{[17]}$ show $100 \%$ dopant activation at $250{ }^{\circ} \mathrm{C}$ encapsulation temperatures. Furthermore, it was shown that epitaxial encapsulation above $270{ }^{\circ} \mathrm{C}$ leads to dopant segregation with no improvement in the quality of overgrowth with a notable $50 \%$ drop in carrier concentration. These data demonstrate the acute importance of strictly limiting the thermal budget to $250{ }^{\circ} \mathrm{C}$ during silicon overgrowth in order to prevent diffusion and segregation of the incorporated phosphorous ${ }^{[18],[19]}$.

Since the temperature required for epitaxial growth $\left(T_{\text {epi }}\right)$ is strongly dependent on the flux rate ${ }^{[20]}$, it is possible to lower $T_{\text {epi }}$ by decreasing the flux rate. Mo et al. ${ }^{[21]}$ showed the formation of Si dimer chains at temperatures ranging from $75^{\circ} \mathrm{C}$ to $227{ }^{\circ} \mathrm{C}$ with low flux rates $(0.1 \mathrm{ML} / \mathrm{min}, \mathrm{ML}=$ monolayer $)$. Earlier studies with extremely low growth rates $(0.06$ $\mathrm{ML} / \mathrm{min}$ ) indicated ordering and epitaxy for sub-monolayer growth at $250{ }^{\circ} \mathrm{C}^{[22]}$. However, these rates are too low and unsuitable for practical atomic device applications that rely $\mathrm{Si}$ overgrowth due to increased contamination and potential segregation. Si crystalline growth quality, purity, and dopant segregation are all critically dependent on growth rates and temperatures.

For device fabrication based on hydrogen resist lithography, a temperature of $250{ }^{\circ} \mathrm{C}$ is not sufficient to remove the hydrogen resist layer and the residual hydrogen dissociated from $\mathrm{PH}_{3}$ precursor that influence the growth quality of the encapsulation layer. Previous studies have shown that $\mathrm{H}$ impurities in the chamber can lead to the breakdown of low temperature silicon epitaxy ${ }^{[14],[23],[24]}$. Lagally et al. ${ }^{[25]}$ reported an increase in Si island density at $177{ }^{\circ} \mathrm{C}$ as hydrogen coverage was increased from $0 \%$ to $8 \%$, and showed that this effect disappeared when the temperature was increased to above $277^{\circ} \mathrm{C}$. Nara et al. ${ }^{[26]}$ have investigated early phase growth formation of one dimensional Si islands on H: Si surface at $277^{\circ} \mathrm{C}$ and $327{ }^{\circ} \mathrm{C}$ with low flux rates $(0.3 \mathrm{ML} / \mathrm{min})$. McKibbin et al. ${ }^{[22]}$ showed that the presence of a hydrogen resist layer results in an overall increase in roughness during $10 \mathrm{~nm}$ to $25 \mathrm{~nm}$ overgrowth. Although there are reports showing epitaxial overgrowth at $250{ }^{\circ} \mathrm{C}$ and more than $20 \mathrm{~nm}$, a comprehensive analysis of the growth morphology from sub monolayer to a target encapsulation thickness $(\sim 25 \mathrm{~nm})$ comparing hydrogen terminated and clean silicon surfaces provides an important understanding of the underlying growth dynamics are essential to optimization. The key emphasis of the work presented here is to demonstrate epitaxial $\mathrm{Si}$ growth on $\mathrm{H}$ : Si and $\mathrm{Si}$ up to nominally $25 \mathrm{~nm}$ thickness while strictly limiting the temperature to $250^{\circ} \mathrm{C}$. We present a systematic study using STM analysis and cross section TEM to examine the epitaxial growth from sub-monolayer coverage $(0.15 \mathrm{ML})$ to $25 \mathrm{~nm}$ thickness at relatively higher flux rates 
from $0.4 \mathrm{ML} / \mathrm{min}$ to $3 \mathrm{ML} / \mathrm{min}$ with comparison to growth on bare Si (100) surfaces. These growth parameters cover an essential range where high quality epitaxy and electrical activation can be achieved in atomic scale devices while minimizing contamination and dopant segregation.

\section{Experimental method}

Front and backside polished $p$ type boron doped Si (100) (thickness of $300 \pm 25 \mu \mathrm{m}$ ) wafers with resistivity of $5 \sim 10$ ohm-cm were used in the experiments. Samples of $4 \mathrm{~mm} \times 10 \mathrm{~mm}$ size were diced from the wafer. The samples were cleaned using a standard piranha and RCA recipe, followed by a dip in $2 \%$ hydrofluoric acid ${ }^{[27],[28]}$. Afterwards, the samples were mounted on a standard Omicron sample holder ${ }^{*}$ and loaded into a UHV preparation chamber with an in situ UHV heater (base pressure $5 \times 10^{-8} \mathrm{~Pa}$ ). Samples were then degassed for 12 hours at $550{ }^{\circ} \mathrm{C}$ by passing current through the sample with additional radiative heating power of nominally $20 \mathrm{~W}$. This was followed by flash heating at $1200{ }^{\circ} \mathrm{C}(2 \sim 3$ times) and annealing for $2 \sim 4$ hours at $1050{ }^{\circ} \mathrm{C}$. The $\mathrm{Si}(100)$ surfaces were passivated at $320{ }^{\circ} \mathrm{C}$ or less by back filling $\mathrm{H}$ to $1.3 \times 10^{-4} \mathrm{~Pa}$ for $10 \mathrm{~min}$ using a filament-type hydrogen cracker $(\mathrm{W}, 0.7 \Omega, 2.6 \mathrm{~A})$. Samples were then transferred to the STM chamber and an RHK Pan Scan STM ${ }^{*}$ was used for room temperature imaging.

An intrinsic silicon sublimation source (SUSI 40) was mounted in the preparation chamber for ultra-pure and low flux Si sublimation. The growth rate as a function of the filament current was calibrated by using a surface profilometer, atomic force microscope, ellipsometer and quartz crystal microbalance (QCM). Fig. 1(a) is a picture of the SUSI 40 showing the intrinsic Si filament arch. Fig. 1(b) compares the real flux rate measurement with specifications at the same deposition distance of $10 \mathrm{~cm}$. The two curves have nearly the same slope indicating the exponential growth rate as a function of filament current. Before Si overgrowth, the sample temperature was monitored by a pyrometer with an uncertainty of $\pm 0.5 \%$ in the $50{ }^{\circ} \mathrm{C}$ to $400{ }^{\circ} \mathrm{C}$ range. Combined with the calibrated QCM monitor, we were able to achieve growth control with a precision of $0.05 \mathrm{ML}$ over the range from sub-monolayer to tens of nanometers.

\section{Experimental results and discussion}

\subsection{Sub-monolayer Si deposition on H: Si (100) and Si (100) surfaces}

Figs. 2(a) and 2(c) show 0.15 ML and 0.4 ML Si deposition on a H terminated Si (100) $2 \times 1$ surface at $250{ }^{\circ} \mathrm{C}$ with the same flux rate of $0.4 \mathrm{ML} / \mathrm{min}$, respectively. Since the temperature of $\mathrm{H}$ desorption from a Si surface is nominally above $400{ }^{\circ} \mathrm{C}^{[29]}$, the underlying Si $2 \times 1$ dimer reconstruction with persistent $\mathrm{H}$ passivation is still clearly visible in both

\footnotetext{
* Certain commercial equipment, instruments, or materials are identified in this paper to foster understanding. Such identification does not imply recommendation or endorsement by the National Institute of Standards and Technology, nor does it imply that the materials or equipment identified are necessarily the best available for the purpose.
} 
STM images. At 0.15 ML, Si adatoms formed clusters containing several atoms. At 0.4 ML coverage, these adatom clusters are much denser and begin to order into short dimer rows, along with a slight increase in the surface room mean square (RMS) roughness from $1.07 \pm 0.11 \AA$ to $1.56 \pm 0.19 \AA$. The island number density calculated from STM images for $0.15 \mathrm{ML}$ and $0.4 \mathrm{ML}$ are estimated to be $3.5 \times 10^{13} / \mathrm{cm}^{2}$ and $5.0 \times 10^{13} / \mathrm{cm}^{2}$, respectively. This corresponds to short $1 \mathrm{D}$ islands with two or three dimers, consistent with Nara's observations at $277{ }^{\circ} \mathrm{C}^{[26]}$. The island number density increases with Si coverage indicating that the adatoms nucleate to form new islands rather than attach to existing islands due to the low $250{ }^{\circ} \mathrm{C}$ growth temperature ${ }^{[30]}$. Although Lagally et al. ${ }^{[25]}$ reported Si island number densities of $2.0 \times 10^{12} / \mathrm{cm}^{2}$ with a $\mathrm{H}$ coverage of $0.08 \%$ at $250{ }^{\circ} \mathrm{C}$, the starting $\mathrm{H}$ surfaces here all have $1 \mathrm{ML}$ of $\mathrm{H}$ that is shown to result in a higher island number density. This demonstrates the influence of significant $\mathrm{H}$ coverage on Si island formation, consistent with the conclusions of Lagally.

Fig. 2(b) and Fig. 2(d) are STM images after a subsequent $500{ }^{\circ} \mathrm{C}$ anneal for $10 \mathrm{~min}$ for both the $0.15 \mathrm{ML}$ and 0.4 ML films respectively. Upon annealing, the small clusters and short rows coalesce to form 2D islands on the Si surface. Note that the second layer of adatoms on top of the clusters in Fig. 2(c) begin to form well-ordered short dimer rows on top of the islands in Fig. 2(d). The surface morphology after $500{ }^{\circ} \mathrm{C}$ anneal agrees with the well-known island growth mode. It should also be noted that the islands in Fig. 2(d) corresponding to a coverage of 0.4 ML have more vacancies in comparison with that in Fig.2 (b) from the 0.15 ML coverage. With the higher deposition amounts, the adatoms tend to form relatively large clusters spontaneously upon deposition [in Fig. 2(c)]. The comparison shows that the larger the cluster size, the lower the mobility which results in an increase in the vacancy density in the islands which is consistent with observations of Oberbeck et al. ${ }^{[31]}$.

Previous studies have shown the rate of desorption peak at about $470{ }^{\circ} \mathrm{C}^{[29]}$, and hence a $500{ }^{\circ} \mathrm{C}$ anneal for 10 min is sufficient to remove nearly all of the $\mathrm{H}$ atoms from the surface. However, from these data it cannot be determined whether $\mathrm{H}$ desorption plays a dominant role in the island growth, since the surface diffusion coefficient $D$ is highly dependent on the substrate temperature $T$ as follows ${ }^{[32]}$ :

$$
\begin{aligned}
& D=a^{2} k_{S} \\
& k_{S} \propto \exp \left\{-V_{S} / k_{B} T\right\}
\end{aligned}
$$

where $a, k_{S}, V_{S}$, and $k_{B}$ represent the effective hopping distance between sites, the hopping rate of an adatom, the potential energy barrier from site to site and the Boltzmann constant, respectively. Based on this theory, a $500{ }^{\circ} \mathrm{C}$ anneal not only would desorb the $\mathrm{H}$ atoms, but also will increase the Si adatom mobility. To better understand this dynamic, we performed controlled Si growth experiments on bare $\mathrm{Si}$ surfaces at $250{ }^{\circ} \mathrm{C}$. 
Fig. 3(a) shows a 0.4 ML Si deposition on bare $\mathrm{Si}(100) 2 \times 1$ surface at $250{ }^{\circ} \mathrm{C}$ with a flux rate of $0.4 \mathrm{ML} / \mathrm{min}$. It is evident from this image that the $\mathrm{Si}$ adatoms tend to form elongated $2 \mathrm{D}$ island chains in the dimer row direction. The silicon atoms have enough mobility to diffuse and form these 2D island chains at this temperature. The second layer begins to form before the first layer completes, which is typical of this growth mechanism ${ }^{[33]}$. This is direct evidence that epitaxial growth of Si on Si (100) surfaces proceeds by an island growth mechanism at this temperature and flux rate. Fig. 3(a) can be compared directly with Fig. 2(a) and 2(c) to show the effect of $\mathrm{H}$ on $\mathrm{Si}$ growth at $250^{\circ} \mathrm{C}$. It is clear from the comparison that $\mathrm{H}$ atoms on $\mathrm{Si}$ decrease the in-plane diffusion of adatoms in the sub-monolayer regime. As a supporting conclusion for the previous studies ${ }^{[23],[34]}$, this comparison directly demonstrates the role of $\mathrm{H}$ atoms on Si diffusion in the sub-monolayer growth regime.

Furthermore, it should also be noted that the 2D islands in Fig. 3(a) are smaller than that in Fig. 2(d), because of the reduced mobility at $250{ }^{\circ} \mathrm{C}$. Upon annealing at $500{ }^{\circ} \mathrm{C}$ for $10 \mathrm{~min}$ the $2 \mathrm{D}$ island chains coalesce to form larger islands as shown in Fig. 3(b) with the inset STM image showing a small compact 2D island. At this temperature the adjacent island chains seen in Fig. 3(a) merge together to form larger elongated islands. A reduced anneal time for this process, rapid thermal anneal ${ }^{[16],[23]}$, has been applied as a strategy to reduce roughness and improve the overgrown surface quality while minimizing higher temperature exposure of the previous temperature sensitive phosphorus processes.

\subsection{Beyond sub-monolayer Si deposition on H: Si (100) and Si (100) surfaces}

Going beyond the sub-monolayer regime and investigating the growth on thicker films, Fig. 4(a) and 4(b) show 1 ML and $7 \mathrm{ML}$ thick Si depositions on $\mathrm{H}$ : Si surfaces at $250{ }^{\circ} \mathrm{C}$, respectively. Compared with sub-monolayer Si growth, the RMS roughness of Fig.4 (a) is reduced to $0.74 \pm 0.05 \AA$ which is the result of the post-deposition surface having more average coverage and the adjacent dimer rows having fewer voids. The adatoms on top of the first layer appear more scattered and isolated in comparison with Fig. 3(a) where adatoms form very compact and well-ordered dimer rows on top of the first layer. As the thickness is increased to $7 \mathrm{ML}$ in Fig. 4(b) there is a considerable increase in RMS roughness to $1.53 \pm 0.15 \AA$ and the substrate step edges are not as well defined as in Fig. 4(a). Although the surface appears rougher with larger clusters, we still observe long range order with perpendicular dimer rows in successive layers, characteristic of an ordered silicon $(2 \times 1)$ reconstructed surface. Fig. 4(c) shows the topography of a $15 \mathrm{~nm}$ Si deposition on $\mathrm{H}$ : Si at $250{ }^{\circ} \mathrm{C}$. Based on the STM image, the RMS surface roughness is $3.72 \pm 0.17 \AA$ with a large distribution of $3 \mathrm{D}$ islands.

Fig. 4(d) shows a cross section TEM image of the $15 \mathrm{~nm}$ Si overgrowth on H: Si surface. The region between the solid lines is the overgrown film and is nominally $15 \mathrm{~nm}$. The TEM image indicates that the growth is epitaxial up to 15 $\mathrm{nm}$ thickness and the overgrown film has very limited defects and the growth seems to proceed with continuous atomic order. Since the STM images show rough surface topography with numerous voids and vacancies at $7 \mathrm{ML}$ and $250{ }^{\circ} \mathrm{C}$, we 
conclude that these vacancies are filled as the growth proceeds due to the recrystallization of the underlying material. This further supports previous arguments in the literature that most $\mathrm{H}$ atoms segregate with the growth front by exchange with incoming $\mathrm{Si}$ ad-atoms ${ }^{[14],[24],[25]}$. The presence of the $\mathrm{H}$ atoms at the growth front increase the roughness surfaces as seen in Fig. 4(a-c). The combined STM and TEM results demonstrate that we can achieve epitaxial growth of Si on H: Si up to 15 $\mathrm{nm}$ thickness at $250{ }^{\circ} \mathrm{C}$. Earlier work by Copel and Tromp ${ }^{[35]}$ reported Si epitaxy temperatures of around $200{ }^{\circ} \mathrm{C}$ on $\mathrm{H}$ : $\mathrm{Si}$ surface, achieving $20 \mathrm{ML}(2.7 \mathrm{~nm})$ of Si on a surface with $1 \mathrm{ML} \mathrm{H}$ coverage. Here we will extend this work by increasing the growth rate and thickness and demonstrate epitaxy on $\mathrm{H}$ : Si up to $25 \mathrm{~nm}$, an essential thickness for practical atomic scale device fabrication. It is essential that this encapsulation layer be crystalline in order to achieve optimum dopant activation and carrier densities. Furthermore, high quality low temperature Si overgrowth not only improves the performance of 2D patterned devices, but also plays an important role in extended applications involving 3D $\operatorname{architectures}^{[2],[36],[37]}$.

In contrast, Fig. 5(a) shows the morphology of $7 \mathrm{ML} \mathrm{Si}$ growth (flux rate: $0.4 \mathrm{ML} / \mathrm{min}$ ) on bare Si (100) surface at $250{ }^{\circ} \mathrm{C}$. Dimer rows typical on the Si (100) $2 \times 1$ surface are observed indicating that the growth is epitaxial. Unlike the isolated 2D island growth shown in Fig. 3(b), this surface exhibits a much denser 3D island growth with long dimer rows on each successive layer rotated by $90^{\circ}$. An $18 \mathrm{~nm}$ thick deposition layer at $250{ }^{\circ} \mathrm{C}$ is shown in Fig. 5(b). The original substrate step and terrace structure is still visible in Fig. 5(b) inset demonstrating that the growth is conformal to the underlying substrate. The morphology of the $7 \mathrm{ML}$ and $18 \mathrm{~nm}$ (Fig. 5(a) and 5(b)) at $250{ }^{\circ} \mathrm{C}$ grown films is very similar indicating that the nature of the growth in this thickness regime is nearly identical. The RMS roughness for 7 ML and 18 nm thick Si overgrowth (shown in Fig. 5(d)) are comparable at $2.88 \pm 0.15 \AA$ and $2.96 \pm 0.10 \AA$, respectively. The data in Fig. 5(d) show that there is no trend of increase in surface roughness in this case as opposed to the case for the H: Si surfaces.

Fig. 5(c) shows one of several high resolution-cross section TEM images obtained from several locations studied on a $15 \mathrm{~nm}$ thick Si deposition on clean $\mathrm{Si}(100)$ at $250{ }^{\circ} \mathrm{C}$. There is again no noticeable interface and the growth continuity supports epitaxial growth interpretation at the thicknesses studied.

For practical atomic scale device applications, growing silicon at a higher rate is preferred to minimize dopant segregation and residual contamination. To further explore this domain, we have grown $25 \mathrm{~nm}$ of silicon at $250^{\circ} \mathrm{C}$ at a growth rate of $3 \mathrm{ML} / \mathrm{min}$. Fig. 6(a) shows STM image that clearly demonstrating long range atomic order. The island growth consists of perpendicular dimer rows between successive layers and is consistent with the starting $\mathrm{Si}(100) 2 \times 1$ reconstructed surface. These STM data show atomic order and confirm that the growth is epitaxial even with these higher growth rates and thicknesses. The large area scan in Fig. 6(b) shows step and terrace patterns and that the original steps 
are likely preserved during the overgrowth. The stability of unique step and terrace patterns during Si overgrowth is useful since local landmarks can be key to identify the location of a nanometer scale patterned area. It should also be noted that since the overgrowth process is quite sensitive to the flux rate and growth temperature, that the specific source used, such as the SUSI source used here, may have an effect on growth and morphology.

\section{Conclusion}

We have demonstrated clear differences in the nature of growth between a bare Si and a H: Si (100) $2 \times 1$ surface starting from the sub-monolayer coverages up to a thickness of nominally $25 \mathrm{~nm}$. It is evident that hydrogen on the silicon substrate significantly influences the growth behavior. On a bare silicon surface the initial growth is found to be epitaxial for temperatures as low as $250{ }^{\circ} \mathrm{C}$ and the growth front continues to proceed epitaxially to a thickness of $18 \mathrm{~nm}$ with a nominally constant surface morphology and roughness. A key observation of this study is that although $\mathrm{H}$ reduces the mobility of in-plane silicon atoms and limits the quality of silicon overgrowth, epitaxial growth is still possible and sufficient for encapsulating patterned phosphorus doped devices. This study also suggests that hydrogen atoms tend to segregate vertically with the growth front by exchange with the incoming $\mathrm{Si}$ adatoms to achieve Si epitaxy for Si overgrowth beyond the $1 \mathrm{ML}$ regime. The growth parameters studied here cover an essential range needed to achieve high quality epitaxy and electrical activation for atomic scale device fabrication while minimizing contamination and dopant segregation.

\section{Acknowledgement}

This work conducted was sponsored by the Innovation Measurement Science project at NIST: Single atom transistors to solid states quantum computing. Xiao Deng thanks the Chinese Sponsorship Council and US government for the sponsorship to be a guest researcher at NIST. This research was performed in part in the NIST CNST NanoFab. 


\section{References}

[1] B. Weber, S. Mahapatra, H. Ryu, S. Lee, A. Fuhrer, T. Reusch, D. Thompson, W. Lee, G. Klimeck, L.C. Hollenberg, Ohm's law survives to the atomic scale, Science, 335 (2012) 64-67.

[2] S. McKibbin, G. Scappucci, W. Pok, M. Simmons, Epitaxial top-gated atomic-scale silicon wire in a three-dimensional architecture, Nanotechnology, 24 (2013) 045303.

[3] M. Fuechsle, S. Mahapatra, F. Zwanenburg, M. Friesen, M. Eriksson, M.Y. Simmons, Spectroscopy of few-electron singlecrystal silicon quantum dots, Nature Nanotechnology, 5 (2010) 502-505.

[4] E. Bussmann, M. Rudolph, G. Subramania, S. Misra, S. Carr, E. Langlois, J. Dominguez, T. Pluym, M. Lilly, M. Carroll, Scanning capacitance microscopy registration of buried atomic-precision donor devices, Nanotechnology, 26 (2015) 085701.

[5] M. Fuechsle, J.A. Miwa, S. Mahapatra, H. Ryu, S. Lee, O. Warschkow, L.C. Hollenberg, G. Klimeck, M.Y. Simmons, A single-atom transistor, Nature Nanotechnology, 7 (2012) 242-246.

[6] B.E. Kane, A silicon-based nuclear spin quantum computer, nature, 393 (1998) 133-137.

[7] F.A. Zwanenburg, A.S. Dzurak, A. Morello, M.Y. Simmons, L.C. Hollenberg, G. Klimeck, S. Rogge, S.N. Coppersmith, M.A. Eriksson, Silicon quantum electronics, Reviews of modern physics, 85 (2013) 961.

[8] C.D. Hill, E. Peretz, S.J. Hile, M.G. House, M. Fuechsle, S. Rogge, M.Y. Simmons, L.C. Hollenberg, A surface code quantum computer in silicon, Science Advances, 1 (2015) e1500707.

[9] J. Lyding, T.C. Shen, J. Hubacek, J. Tucker, G. Abeln, Nanoscale patterning and oxidation of H-passivated Si (100)-2× 1 surfaces with an ultrahigh vacuum scanning tunneling microscope, Applied physics letters, 64 (1994) 2010-2012.

[10] D.K. Ferry, Ohm's Law in a Quantum World, Science, 335 (2012) 45-46.

[11] S. Schofield, N. Curson, M. Simmons, F. Rueß, T. Hallam, L. Oberbeck, R. Clark, Atomically precise placement of single dopants in Si, Physical review letters, 91 (2003) 136104.

[12] A. Fuhrer, M. Fuchsle, T. Reusch, B. Weber, M. Simmons, Atomic-scale, all epitaxial in-plane gated donor quantum dot in silicon, Nano letters, 9 (2009) 707-710.

[13] H.J. Gossmann, E. Schubert, D. Eaglesham, M. Cerullo, Low-temperature Si molecular beam epitaxy: Solution to the doping problem, Applied physics letters, 57 (1990) 2440-2442.

[14] D. Eaglesham, Semiconductor molecular-beam epitaxy at low temperatures, Journal of applied physics, 77 (1995) 3597 3617.

[15] D. Eaglesham, H.-J. Gossmann, M. Cerullo, Limiting thickness h epi for epitaxial growth and room-temperature Si growth on Si (100), Physical review letters, 65 (1990) 1227.

[16] J.G. Keizer, S. Koelling, P.M. Koenraad, M.Y. Simmons, Suppressing Segregation in Highly Phosphorus Doped Silicon Monolayers, (2015).

[17] S. McKibbin, W. Clarke, A. Fuhrer, T. Reusch, M. Simmons, Investigating the regrowth surface of Si: P $\delta$-layers toward vertically stacked three dimensional devices, Applied Physics Letters, 95 (2009) 233111.

[18] L. Oberbeck, N. Curson, M. Simmons, R. Brenner, A. Hamilton, S. Schofield, R. Clark, Encapsulation of phosphorus dopants in silicon for the fabrication of a quantum computer, Applied physics letters, 81 (2002) 3197-3199.

[19] K. Goh, L. Oberbeck, M. Simmons, A. Hamilton, R. Clark, Effect of encapsulation temperature on Si: P $\delta$-doped layers, Applied physics letters, 85 (2004) 4953-4955.

[20] Z. Zhang, F. Wu, M.G. Lagally, An atomistic view of Si (001) homoepitaxy 1, Annual review of materials science, 27 (1997) 525-553.

[21] Y. Mo, J. Kleiner, M. Webb, M. Lagally, Activation energy for surface diffusion of Si on Si (001): A scanning-tunnelingmicroscopy study, Physical review letters, 66 (1991) 1998.

[22] S.R. McKibbin, Towards Three Dimensional All-Epitaxial Silicon Architectures Patterned By Scanning Tunnelling Microscopy, in, The University of New South Wales, 2012.

[23] P. Asoka-Kumar, S. Szpala, B. Nielsen, C. Szeles, K. Lynn, W. Lanford, C. Shepard, H.-J. Gossmann, Hydrogen-induced breakdown of low-temperature molecular-beam epitaxy of Si, Physical Review B, 51 (1995) 4630.

[24] D. Eaglesham, F. Unterwald, H. Luftman, D. Adams, S. Yalisove, Effect of H on Si molecular-beam epitaxy, Journal of applied physics, 74 (1993) 6615-6618.

[25] J. Vasek, Z. Zhang, C. Salling, M. Lagally, Effects of hydrogen impurities on the diffusion, nucleation, and growth of Si on Si (001), Physical Review B, 51 (1995) 17207.

[26] J. Nara, H. Kajiyama, T. Hashizume, Y. Suwa, S. Heike, S. Matsuura, T. Hitosugi, T. Ohno, Formation Mechanism of OneDimensional Si Islands on a H/Si (001) Surface, Physical review letters, 100 (2008) 026102.

[27] A. Ishizaka, Y. Shiraki, Low temperature surface cleaning of silicon and its application to silicon MBE, Journal of the Electrochemical Society, 133 (1986) 666-671.

[28] K. Li, N. Pradeep, S. Chikkamaranahalli, G. Stan, R. Attota, J. Fu, R. Silver, Controlled formation of atomic step morphology on micropatterned Si (100), Journal of Vacuum Science \& Technology B, 29 (2011) 041806.

[29] L.Y. Ming, D. Vitkavage, B. Meyerson, Doping reaction of PH3 and B2H6 with Si (100), Journal of applied physics, 59 (1986) 4032-4037.

[30] C. Pearson, M. Krueger, E. Ganz, Direct tests of microscopic growth models using hot scanning tunneling microscopy movies, Physical review letters, 76 (1996) 2306.

[31] L. Oberbeck, T. Hallam, N.J. Curson, M.Y. Simmons, R.G. Clark, STM investigation of epitaxial Si growth for the fabrication of a Si-based quantum computer, Applied surface science, 212 (2003) 319-324. 
[32] Z. Zhang, M.G. Lagally, Atomistic processes in the early stages of thin-film growth, Science, 276 (1997) $377-383$.

[33] Y.W. Mo, R. Kariotis, B. Swartzentruber, M. Webb, M. Lagally, Scanning tunneling microscopy study of diffusion, growth, and coarsening of Si on Si (001), Journal of Vacuum Science \& Technology A, 8 (1990) 201-206.

[34] J.-Y. Ji, T.-C. Shen, Low-temperature silicon epitaxy on hydrogen-terminated Si (001) surfaces, Physical Review B, 70 (2004) 115309.

[35] M. Copel, R. Tromp, H coverage dependence of Si (001) homoepitaxy, Physical review letters, 72 (1994) 1236.

[36] S.R. McKibbin, W.R. Clarke, A. Fuhrer, M.Y. Simmons, Optimizing dopant activation in Si: P double $\delta$-layers, Journal of Crystal Growth, 312 (2010) 3247-3250.

[37] J.G. Keizer, S.R. McKibbin, M.Y. Simmons, The Impact of Dopant Segregation on the Maximum Carrier Density in Si: P Multilayers, ACS nano, 9 (2015) 7080-7084. 
(a)

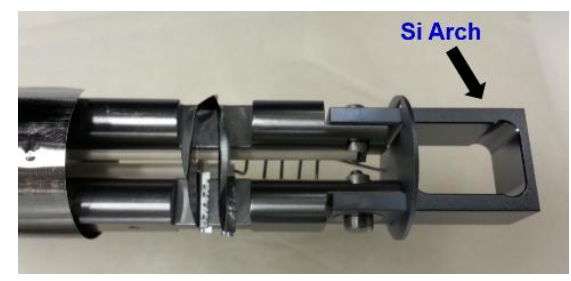

(b)

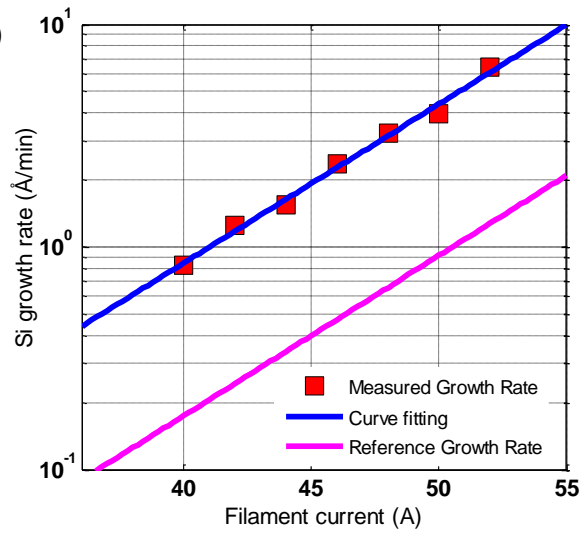

Fig. 1(a) Main parts of the intrinsic Si sublimation source and (b) amorphous growth rate as a function of filament current.

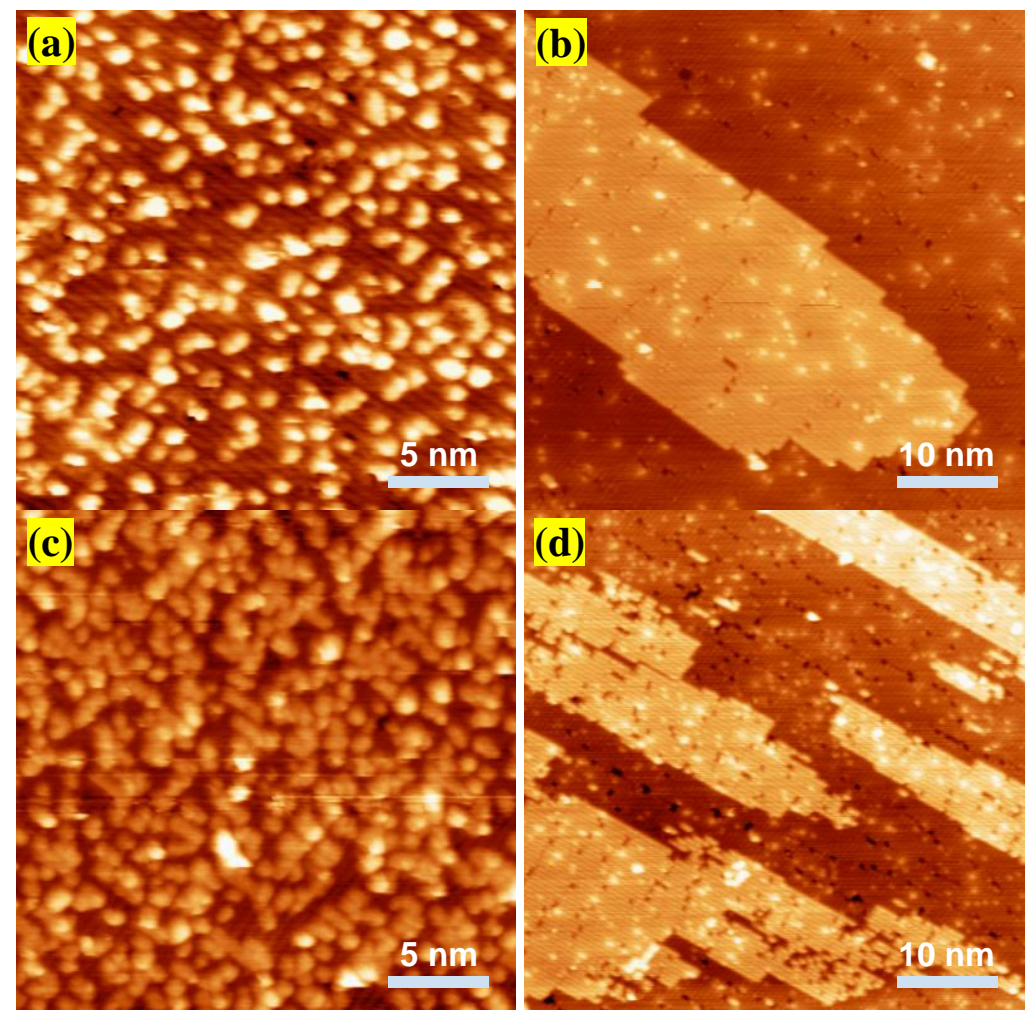

Fig. 2 Empty states STM images of (a) $0.15 \mathrm{ML}$ and (c) $0.4 \mathrm{ML}$ Si deposition on $\mathrm{H}$ terminated $\mathrm{Si}$ (100) surface at $250^{\circ} \mathrm{C}$ with a deposition rate of $0.4 \mathrm{ML} / \mathrm{min}$; (b) and (d) are subsequent annealing at $500^{\circ} \mathrm{C}$ for $10 \mathrm{~min}$ and $\mathrm{H}$ terminated at $320^{\circ} \mathrm{C}$ for (a) and (c), respectively. 


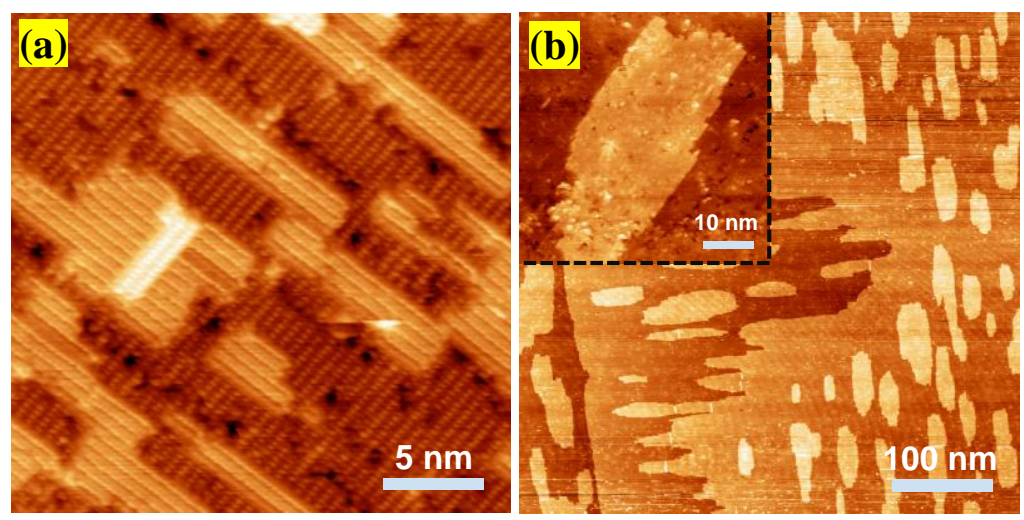

Fig. 3 Empty states STM images of (a) $0.4 \mathrm{ML}$ Si deposition on bare Si (100) surface at $250^{\circ} \mathrm{C}$ (deposition rate is $0.4 \mathrm{ML} / \mathrm{min}$ ) and $\mathrm{H}$ terminated at $140^{\circ} \mathrm{C}$; (b) after annealing at $500^{\circ} \mathrm{C}$ for $10 \mathrm{~min}$ and $\mathrm{H}$ terminated at $320^{\circ} \mathrm{C}$. The inset STM image shows a compact island formed after $500^{\circ} \mathrm{C}$ annealing in another identical experiment.
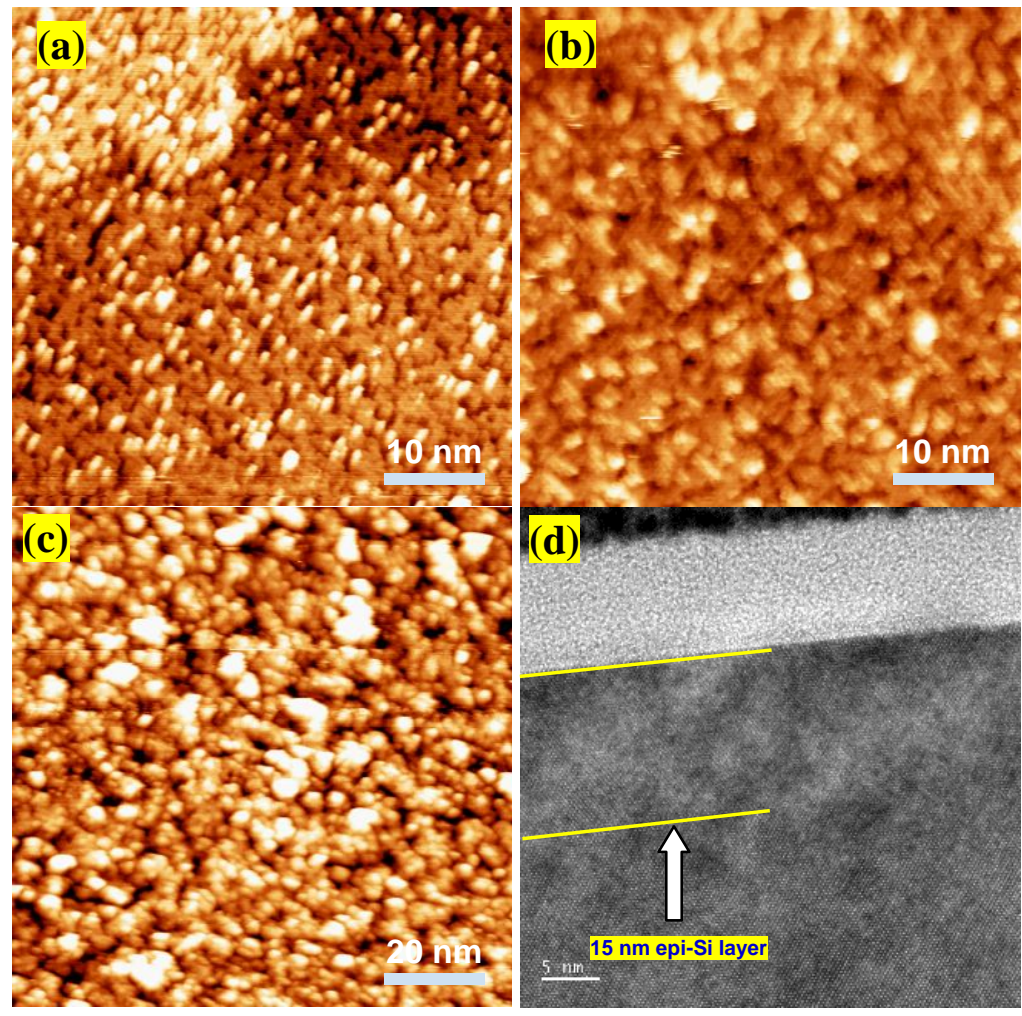

Fig. 4 Empty states STM images of (a) $1 \mathrm{ML}$ and (b) $7 \mathrm{ML}$ Si deposition on $\mathrm{H}$ terminated $\mathrm{Si}$ (100) surface at $250^{\circ} \mathrm{C}$ with a deposition rate of $0.4 \mathrm{ML} / \mathrm{min}$ and $\mathrm{H}$ termination at $250^{\circ} \mathrm{C}$; (c) and (d) are STM image and cross section TEM image of a $15 \mathrm{~nm}$ Si deposition on $\mathrm{H}$ terminated $\mathrm{Si}(100)$ surface at $250^{\circ} \mathrm{C}$ with a deposition rate of $1.2 \mathrm{ML} / \mathrm{min}$. 

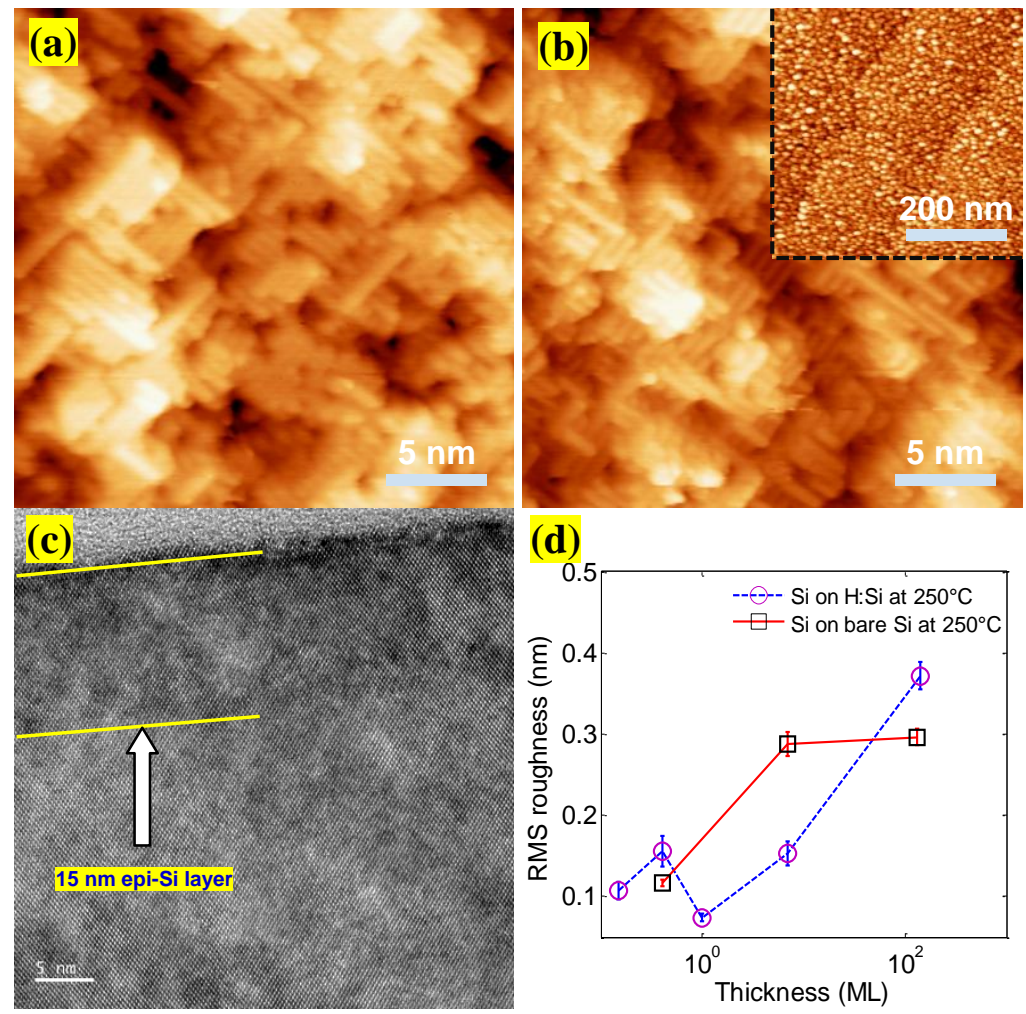

Fig. 5(a) Empty states STM image of $7 \mathrm{ML}$ Si deposition on bare $\mathrm{Si}$ (100) surface at $250^{\circ} \mathrm{C}$ with a deposition rate of $0.4 \mathrm{ML} / \mathrm{min}$ and $\mathrm{H}$ terminated at $140^{\circ} \mathrm{C}$; (b) STM images of a $18 \mathrm{~nm}$ Si deposition on bare $\mathrm{Si}(100)$ surface at $250^{\circ} \mathrm{C}$ with a deposition rate of $1.2 \mathrm{ML} / \mathrm{min}$ and then $\mathrm{H}$ terminated at $250^{\circ} \mathrm{C}$; (c)cross section TEM image of an identical $15 \mathrm{~nm} \mathrm{Si}$ deposition on bare $\mathrm{Si}(100)$ surface at $250^{\circ} \mathrm{C}$ with a deposition rate of $1.2 \mathrm{ML} / \mathrm{min}$;(d) RMS roughness of $\mathrm{Si}$ grown on $\mathrm{Si}$ and $\mathrm{H}: \mathrm{Si}$ at $250^{\circ} \mathrm{C}$ in this letter. The selected area for each RMS roughness calculation is $20 \mathrm{~nm} \times 20 \mathrm{~nm}$.
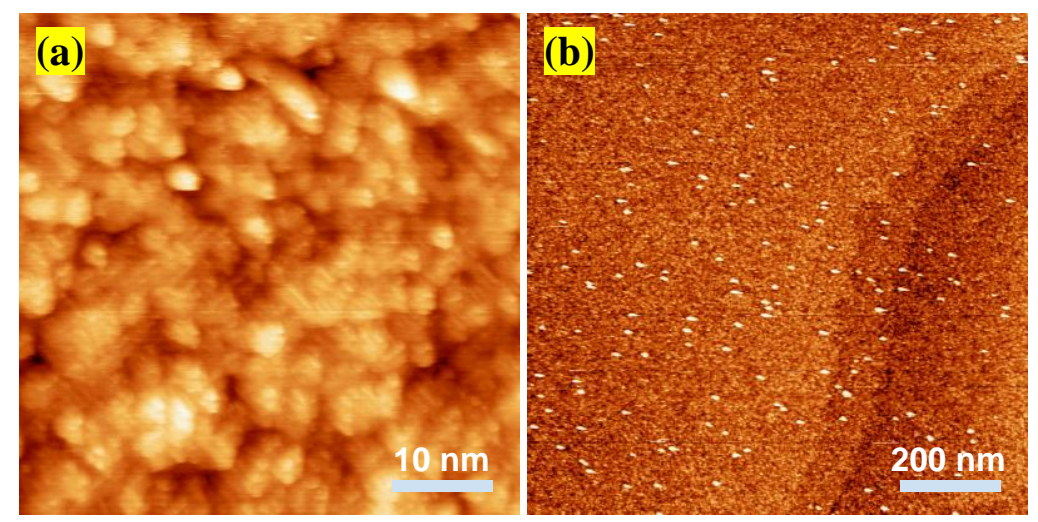

Fig. 6 Empty state STM images showing $25 \mathrm{~nm}$ Si deposition on $\mathrm{H}$ : $\mathrm{Si}$ surface at $250^{\circ} \mathrm{C}$ with a deposition rate of 3 $\mathrm{ML} / \mathrm{min}$ and $140^{\circ} \mathrm{C} \mathrm{H}$ termination: (a) $50 \mathrm{~nm} \times 50 \mathrm{~nm}$; (b) $1 \mu \mathrm{m} \times 1 \mu \mathrm{m}$. The original step and terrace structures are still visible after $25 \mathrm{~nm}$ Si overgrowth on $\mathrm{H}: \mathrm{Si}(100)$. 